Article

\title{
An Economical Method for Simultaneously Improving Pretreatment and Anaerobic Fermentation Effects on Corn Straw Using Ultra-Low Concentration $\mathrm{FeCl}_{2}$
}

\author{
Yina Qiao ${ }^{1,2}$, Xuebin Lu ${ }^{1,3}$, Zehao Zhi ${ }^{4}$ and Shuting Zhang ${ }^{1, *}$ \\ 1 School of Environment Science and Engineering, Tianjin University, Tianjin 300072, China; \\ qiaoyina@nuc.edu.cn (Y.Q.); xbltju@tju.edu.cn (X.L.) \\ 2 School of Environment and Safety Engineering, North University of China, Taiyuan 030051, China \\ 3 School of Science, Tibet University, Lhasa 850000, China \\ 4 Tianjin Environmental Protection Technical Development Center, Tianjin 300191, China; \\ ZehaoZhi@tju.edu.cn \\ * Correspondence: zhangst@tju.edu.cn; Tel.: +86-27-87794549
}

Received: 10 March 2020; Accepted: 1 April 2020; Published: 7 April 2020

\begin{abstract}
Low pollution, slight corrosion, and low cost are the main challenges in the conversion of biomass to biogas. In this work, based on the whole process optimization of biomass conversion, an effective method using an ultra-low concentration of $\mathrm{FeCl}_{2}$ was proposed to simultaneously promote the biochemical reaction and improve the pretreatment effect. The concentration of $\mathrm{FeCl}_{2}$ in the pretreatment was determined according to the requirements of the minimum amount which led to the optimal performance of the anaerobic system and had economical importance. The effects of $\mathrm{FeCl}_{2}$ in the pretreatment and anaerobic fermentation were evaluated by comparing with that of distilled water in the production of hydrolysis products and organic acids. The optimal condition was obtained at $180{ }^{\circ} \mathrm{C}$ and $10 \mathrm{~min}$ with $1 \times 10^{-5} \mathrm{~mol} / \mathrm{L} \mathrm{FeCl}_{2}$ pretreatment. At that condition, hemicellulose achieved a high conversion of $97.6 \%$, and the released xylose reached nearly $95 \%$. At least $77.5 \%$ of the organic matter in the solution can be utilized for subsequent fermentation. $\mathrm{FeCl}_{2}$ pretreatment also accelerated the anaerobic acidification fermentation process and promoted organic acid yields. The work provided a meaningful and economical choice for the conversion technology of biomass to biogas.
\end{abstract}

Keywords: $\mathrm{FeCl}_{2}$; pretreatment; catalyst; ultra-low concentration; anaerobic fermentation; biogas; nutritional components; whole process optimization; corn straw

\section{Introduction}

Lignocellulose materials draw a lot of attention because they are abundant, low-priced, and renewable. Furthermore, they play a significant role in the utilization of alternative energy sources in the future which can be used to produce biofuels, such as biogas or bioethanol. Reasonable utilization of lignocellulose biomass can reduce $\mathrm{CO}_{2}$ emissions [1,2]. To improve lignocellulose utilization efficiency, destroying the complex rigid structure of lignocellulose becomes the main challenge in the conversion from biomass to biofuel [3]. The conversion process is generally considered to have three steps: pretreatment, enzymatic hydrolysis, and fermentation to produce biofuel [4]. Pretreatment is considered the most important and efficient step for the degradation of lignocellulose [5]. It can break the lignin envelope and liberate its crystalline structure to be used more easily in the subsequent hydrolysis process [6]. 
At present, many kinds of pretreatment methods have been tested, including dilute acid $[7,8]$, alkaline [9,10], liquid hot water [11,12], steam explosion [13,14], ionic liquid [15,16], and so on. Among these methods, dilute acid is considered low-cost for lignocellulose conversion, which can significantly enhance xylose yields from hemicellulose and expose cellulose to enzymes for high yields from subsequent hydrolysis [17-20]. However, the strong equipment-corrosion and harmful by-products can still not be completely resolved during the dilute acid pretreatment process. Besides that, the addition of reagents needs to be considered at different reaction stages for green technology [6]. Avoiding the repeated addition of reagents can simplify the reaction process, thereby saving human and financial resources. Therefore, to find suitable catalysts, which play a part in both pretreatment and fermentation, is vital for the overall process of lignocellulose conversion to biofuel.

Some researchers have found that inorganic salts, especially iron salts, can improve the hydrolysis effect of lignocellulose with the different pretreatment processes. $\mathrm{FeCl}_{3}$ is an effective catalyst for the hydrolysis of peat with $\mathrm{HCl}$ [21]. In corn stalk, $0.1 \mathrm{~mol} / \mathrm{L} \mathrm{FeCl}_{3}$ can release about $90 \%$ of xylose between $140{ }^{\circ} \mathrm{C}$ and $200{ }^{\circ} \mathrm{C}$ for $20 \mathrm{~min}$ [22]. $\mathrm{Fe}\left(\mathrm{NO}_{3}\right)_{3}$ as a catalyst, is found to be more efficient than other inorganic salts, such as $\mathrm{FeSO}_{4}, \mathrm{FeCl}_{3}, \mathrm{Fe}_{2}\left(\mathrm{SO}_{4}\right)_{3}$, for corn straw silages pretreatment [23]. $\mathrm{FeSO}_{4}$ can enhance enzymatic hydrolysis and encourage the inversion of chemical composition and structure in corn stalk. This is because $\mathrm{Fe}^{2+}$ can adsorb at the positions of $\mathrm{C}_{2}, \mathrm{C}_{3}, \mathrm{C}_{6}, \mathrm{O}_{5}$ of the cellulose pyran ring and make the pyran ring bond rupture, which result in the crystalline structure of cellulose breaking and the surface area improving [4]. $\mathrm{FeCl}_{2}$ is found to improve the degradation of both xylose and furfural, and about $60 \%$ xylan is turned into non-saccharide products in sweet sorghum bagasse with liquid hot water [24].

In addition to serving as a catalyst in lignocellulose pretreatment, the iron element is found to play an important role as the nutrient additive in anaerobic fermentation $[25,26]$. Iron as a trace metal not only participates in the synthesis of anaerobes, but also often appears in the enzyme system of anaerobes as coenzymes, cofactors, and electron acceptors, and has a stimulatory effect on the methane production stage of anaerobes $[27,28]$. It can provide nutrition to the bacteria and promote microbiological activity. Organic matter is degraded to biogas and its methane content is increased by trace metals [29-31]. Adding iron also speeds up the degradation of volatile fatty acids accumulated [32]. Therefore, the effects of iron salts are reflected in a series of the biomass conversion process, as shown in Figure 1.

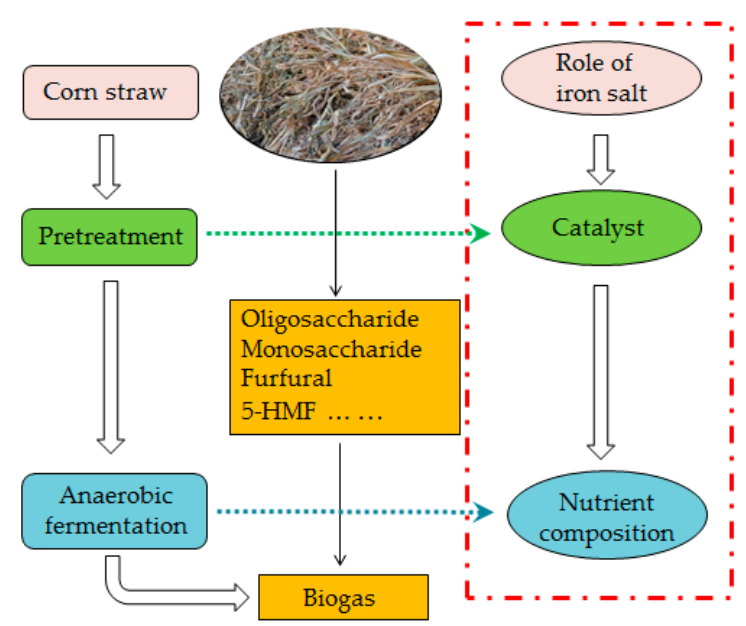

Figure 1. Role of iron salt in the whole process from lignocellulose to biogas.

As a trace nutritional supplement, the minimum concentration of iron salt is recommended to obtain economic importance for optimal performance of the anaerobic system, since the addition of trace elements may increase the operating costs of the process. A more thorough understanding of the minimum amount will allow a more economical and effective control of the process [33,34]. Some studies have explored the concentration of $\mathrm{Fe}^{2+}$ or $\mathrm{FeCl}_{2}$ to the anaerobic system. Additives of 
$10 \mathrm{mg} / \mathrm{L} \mathrm{Fe}^{2+}$ every 45 days at a hydraulic residence time (HRT) of 30 days can successfully perform the methane fermentation [31]. The minimum requirement of iron added in the mesophilic fermentation is $1.9 \pm 0.1 \mathrm{mg} / \mathrm{L}$ [28]. Adding $1 \mathrm{mg} / \mathrm{L} \mathrm{FeCl} 2 \cdot 4 \mathrm{H}_{2} \mathrm{O}$ into the reactor volume of $1 \mathrm{~L}$ every day is suggested to reduce the concentration of volatile acids in the fermentation [35]. To improve the conversion of acetic acid to methane, the optimum dissolved iron concentration is recommended between 25.4 and $253.5 \mathrm{mg} / \mathrm{L}$ [36]. Since the biomass originally contains a certain concentration of $\mathrm{Fe}^{2+}$, the additives of $\mathrm{Fe}^{2+}$ should be limited at $1.3-2.5 \mathrm{mg} / \mathrm{L}$ in the anaerobic system [37]. Based on the above research results, the minimum amount of $\mathrm{FeCl}_{2}$ in the anaerobic system should be as low as $1 \mathrm{mg} / \mathrm{L}$. The concentration of $\mathrm{FeCl}_{2}$ in the pretreatment process should also be as low as possible so that $\mathrm{Fe}^{2+}$ in the hydrolysate can meet the minimum concentration requirements of the anaerobic system.

The main goal of the work was to investigate the influence of an ultra-low concentration $\mathrm{FeCl}_{2}$ on both pretreatment and anaerobic fermentation in view of the whole process optimization. The catalytic property of $\mathrm{FeCl}_{2}$ and its effect of pretreatment on corn straw conversion were evaluated. Further, the role of $\mathrm{FeCl}_{2}$ in anaerobic fermentation was studied by acidogenic fermentation with the hydrolyzate at the optimal condition of $\mathrm{FeCl}_{2}$ pretreatment.

\section{Materials and Methods}

\subsection{Raw Materials and Sample Preparation}

All corn straw used in the study was taken from Wuqing, Tianjin, China. The air-dried crop samples were first cut into about $2-3 \mathrm{~cm}$ segments with a hay cutter, then ground several times until they all passed through a 20-mesh sieve, and finally stored in a polyethylene container at room temperature for use. They were dried at $60{ }^{\circ} \mathrm{C}$ before pretreatment to avoid the effect of moisture during storage.

The analytical procedure of National Renewable Energy Laboratory (NREL) [38] was performed to measure the components of corn straw, including cellulose, hemicellulose, lignin, and ash in biomass samples. The main components of corn straw raw material were cellulose $38 \mathrm{~g}$, hemicellulose $21.8 \mathrm{~g}$ (containing $17.7 \mathrm{~g}$ xylan and $4.1 \mathrm{~g}$ arabinan), lignin $6.9 \mathrm{~g}$, ash $4.3 \mathrm{~g}$, and others $29 \mathrm{~g}$ in $100 \mathrm{~g}$ dry matter $(\mathrm{DM})$.

\subsection{Pretreatment Experimental Setup}

Pretreatment was performed by the in-house-built laboratory-scale salt bath equipment (Figure 2). It included an electric controller, an electric mixer, and a salt bath. Hydrothermal reactions took place in the stainless steel cylindrical reactor tank with a total volume of $200 \mathrm{~mL}$ and were monitored by matching temperature sensors. The temperature of the salt bath was balanced through the mixer and the temperature of the reaction was regulated by the electric controller. The salt bath with a liquid mixture of $\mathrm{KNO}_{3}$ and $\mathrm{NaNO}_{2}$ in a proportion 1:1 was used to give the needed temperature. The highest temperature and the maximum pressure that the reactor could withstand were $300^{\circ} \mathrm{C}$ and $40 \mathrm{MPa}$, respectively. The average heating rate was about $20-30{ }^{\circ} \mathrm{C} \mathrm{min}^{-1}$. When the designed temperature inside the reactor was reached, the pretreatment time started to be counted. After reaching the targeted time, the reactor was taken out from the salt bath and sunk into a cold water bath for cooling to below $50{ }^{\circ} \mathrm{C}$. The mixture after the reaction was filtrated by a vacuum pump, obtaining a solid phase and a liquid phase. The solid phase was washed with deionized water, weighed and analyzed for lignin and ash according to the NREL analytical approach. The liquid phase was analyzed to use HPLC for the degradation products, such as glucose, xylose, arabinose, formic acid, acetic acid, furfural, 5-hydroxymethyl furfural (5-HMF), and levulinic acid.

\subsection{Determination and Analysis of Samples}

The concentrations of oligosaccharide, single-molecule, and volatile fatty acids in the hydrolysis products were all quantified by a High-Performance Liquid Chromatography (HPLC) system (Shimazu, 
LC-20A) equipped with Bio-Rad Aminex column (HPX-87H, $7.8 \mathrm{~mm}$ ). Of all the products, saccharides including glucose, xylose, and arabinose, and organic acids including formic acid, acetic acid, propionic acid, butyric acid, and isovaleric acid, were measured by a refractive index detector. The hydrolysis byproducts such as furfural, 5-HMF, and levulinic acid were measured with an ultraviolet detector. The mobile phase was $5 \mathrm{mmol} / \mathrm{L} \mathrm{H}_{2} \mathrm{SO}_{4}$ at a flow rate of $0.6 \mathrm{~mL} / \mathrm{min}$ with a column-oven temperature set at $65^{\circ} \mathrm{C}$.

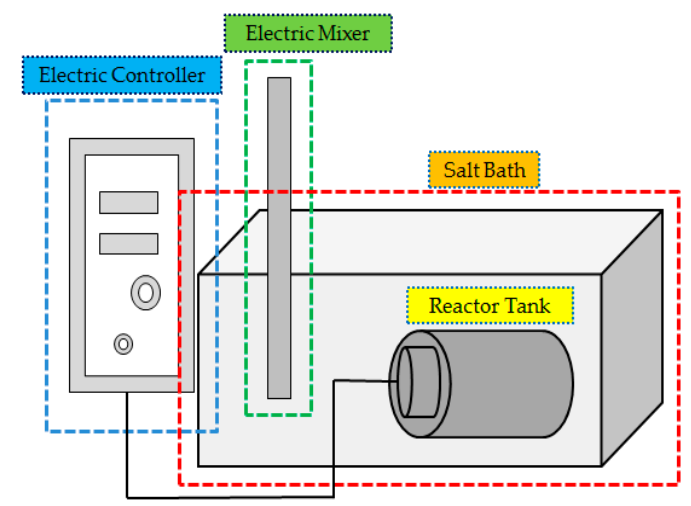

Figure 2. In-house-built salt bath reaction device and reactor tank.

Chemical Oxygen Demand (COD) in the hydrolysis products was determined according to the national standard (China, 2002). The sample digestion process was accelerated by a microwave oven (KDB-III, Qingdao, China). The measurement process was carried out according to the instructions for the microwave oven. A digital $\mathrm{pH}$-meter (pHS-3C, China) was used to determine the $\mathrm{pH}$ in the work. A scanning electron microscope (SEM) (Zeiss Supra 55, Germany) was used to compare the pretreatment effect on straw micromorphology by distilled water and an ultra-low concentration of $\mathrm{FeCl}_{2}$.

Total sugar included glucose, xylose, and arabinose. Total by-products obtained included furfural, 5-HMF, formic acid, and levulinic acid. Available products were the sum of total sugar and total by-products at a certain pretreatment condition. The amount of cellulose conversion refers to the total yields of the main products such as glucose, 5-HMF, formic acid, and levulinic acid after cellulose hydrolysis. The amount of hemicellulose conversion refers to the total yields of the main products such as xylose, arabinose, and furfural after hemicellulose hydrolysis. Cellulose conversion and hemicellulose conversion are defined as follows:

$$
\begin{gathered}
\text { Cellulose conversion }(\%)=\frac{\text { Cellulose hydrolysates in solution }(g)}{\text { Cellulose content in corn straw }(g)} \times 100 \% \\
\text { Hemicellulose conversion }(\%)=\frac{\text { Hemicellulose hydrolysates in solution }(g)}{\text { Hemicellulose content in corn straw }(g)} \times 100 \%
\end{gathered}
$$

\subsection{Combined Severity Analysis}

Combined severity $(C S)$ is an effective parameter for analyzing the hydrolysis degree which correlates three important factors including temperature, time, and catalyst concentration [39]. It helps to evaluate and model the pretreatment process faster [40]. The severity factor is defined as follows [39,41,42]:

$$
\begin{gathered}
C S=\log \left(R_{0}\right) \text { (Hydrothermal pretreatment) } \\
C S=\log \left(R_{0^{\prime}}\right)=\log \left(R_{0}\right)+\log \left[H^{+}\right] \text {(Acid pretreatment) }
\end{gathered}
$$

In Equation (4), the acid pretreatment is mainly aimed at the influence of dilute acid, so $\left[\mathrm{H}^{+}\right] \mathrm{can}$ be calculated directly by acid concentration. However, hydrogen ion concentration in the solution is 
not equivalent to the concentration of catalyst with $\mathrm{FeCl}_{2}$ pretreatment. Therefore, combined severity should be calculated by the following equation:

$$
C S=\log \left(R_{0^{\prime}}\right)=\log \left(R_{0}\right)-\mathrm{pH}
$$

$R_{0}$, respects the severity parameter, which analyzes and evaluates the influence of reaction temperature and reaction time on the pretreatment. $R_{0}$, is defined as follows [40]:

$$
R_{0}=t \times \exp \left[\left(T_{H}-T_{R}\right) / 14.75\right]
$$

$t$, respects the reaction time (min). $T_{H}$ is the reaction temperature $\left({ }^{\circ} \mathrm{C}\right)$, and $T_{R}$ is the reference temperature, which is generally regarded as $100^{\circ} \mathrm{C}$.

\subsection{Pretreatment Schemes}

In order to investigate the catalysis of an ultra-low concentration of $\mathrm{FeCl}_{2}$, distilled water was used for pretreatment comparison. In view of the whole process optimization and the requirements of the minimum amount limited in the anaerobic system, the concentration of $\mathrm{FeCl}_{2}$ was set to lower values, $5 \times 10^{-4} \mathrm{~mol} / \mathrm{L}, 1 \times 10^{-4} \mathrm{~mol} / \mathrm{L}, 5 \times 10^{-5} \mathrm{~mol} / \mathrm{L}$, and $1 \times 10^{-5} \mathrm{~mol} / \mathrm{L}$. The mass ratio of corn straw to $\mathrm{FeCl}_{2}$ solution was set at 1:20. Pretreatment experiments were carried out at the temperature range of $160-220^{\circ} \mathrm{C}$ and the time of $20 \mathrm{~min}$. To evaluate the ultra-low centration $\mathrm{FeCl}_{2}$ in more detail, more pretreatment experiments were carried out at the temperature range of $160-220^{\circ} \mathrm{C}$ and the time range of $10-40 \mathrm{~min}$. Meanwhile, $\mathrm{FeCl}_{2}$ solution was prepared when it was used in the experiment, to prevent $\mathrm{Fe}^{2+}$ from being oxidized.

The work schemes with about $1 \times 10^{-5} \mathrm{~mol} / \mathrm{L} \mathrm{FeCl}_{2}$ pretreatment were shown in Table 1 . Different schemes had different $\mathrm{pH}$, temperature, and time with $1 \times 10^{-5} \mathrm{~mol} / \mathrm{L} \mathrm{FeCl}_{2}$ pretreatment. In order to investigate the influence of $1 \times 10^{-5} \mathrm{~mol} / \mathrm{L} \mathrm{FeCl}_{2}$ more comprehensively, the temperature was set to a relatively wide range of $160-240{ }^{\circ} \mathrm{C}$. The $\mathrm{pH}$ before the reaction fluctuated between 5.75 and 5.9 due to an error. To reduce experimental errors, each experimental result is the average of three repeated experiments under the same conditions.

Table 1. Pretreatment schemes with $1 \times 10^{-5} \mathrm{~mol} / \mathrm{L} \mathrm{FeCl}_{2}, \mathrm{pH}$ before and after reaction and CS.

\begin{tabular}{cccccc}
\hline Run & $\mathbf{T} /{ }^{\circ} \mathbf{C}$ & $\mathbf{t} / \mathbf{m i n}$ & $\mathbf{p H}(\mathbf{B R})$ & $\mathbf{p H}(\mathbf{A R})$ & $\mathbf{l g} \boldsymbol{R}_{\mathbf{0}}{ }^{\prime}(\mathbf{C S})$ \\
\hline 1 & 160 & 10 & 5.85 & 4.72 & -3.08 \\
2 & 160 & 20 & 5.88 & 4.33 & -2.81 \\
3 & 160 & 30 & 5.87 & 4.16 & -2.63 \\
4 & 160 & 40 & 5.86 & 4.05 & -2.49 \\
5 & 180 & 10 & 5.76 & 3.95 & -2.4 \\
6 & 180 & 20 & 5.8 & 3.75 & -2.14 \\
7 & 180 & 30 & 5.79 & 3.48 & -1.96 \\
8 & 180 & 40 & 5.83 & 3.12 & -1.87 \\
9 & 200 & 10 & 5.77 & 3.44 & -1.83 \\
10 & 200 & 20 & 5.81 & 3.35 & -1.56 \\
11 & 200 & 30 & 5.8 & 3.21 & -1.38 \\
12 & 200 & 40 & 5.79 & 3.11 & -1.24 \\
13 & 220 & 10 & 5.86 & 3.1 & -1.33 \\
14 & 220 & 20 & 5.9 & 3.2 & -1.07 \\
15 & 220 & 30 & 5.81 & 3.08 & -0.8 \\
16 & 220 & 40 & 5.84 & 3.21 & -0.7 \\
17 & 240 & 10 & 5.82 & 3.12 & -0.7 \\
18 & 240 & 20 & 5.8 & 3.16 & -0.38 \\
19 & 240 & 30 & 5.78 & 3.13 & -0.18 \\
20 & 240 & 40 & 5.75 & 3.05 & -0.03 \\
\hline
\end{tabular}

Legend. BR and AR represent before the reaction and after the reaction, respectively. 


\subsection{Anaerobic Acidification Fermentation}

The seed sludge came from an anaerobic fermentation tank at medium temperature $\left(37 \pm 1{ }^{\circ} \mathrm{C}\right)$ utilizing pig manure. Anaerobic acidification fermentation was performed in two reagent bottles (numbered $1^{\#}$ and $2^{\#}$ ) with a total volume of $1 \mathrm{~L}$ and a working volume of $800 \mathrm{~mL}$. The hydrolysate from $1 \times 10^{-5} \mathrm{~mol} / \mathrm{L} \mathrm{FeCl}_{2}$ pretreatment optimum condition was added in the bottle $1^{\#}$. Distilled water was added into bottle $2^{\#}$ for comparison. The two reagent bottles were placed in the water bath shaker at $37 \pm 1{ }^{\circ} \mathrm{C}$. The mixed liquor volatile suspended solids (MLVSS) were determined according to the standard methods [43]. The sludge concentration in the bottle was $4000 \mathrm{mg}$ MLVSS/L and the organic load was $1.0 \mathrm{~g}$ COD/g MLVSS $[44,45]$ at the beginning of the acidification fermentation. Regulating the $\mathrm{pH}$ value was $7.0 \pm 0.05$ before fermentation.

\section{Results and Discussion}

\subsection{Catalytic Role of $\mathrm{FeCl}_{2}$ in Pretreatment}

\subsubsection{Comparison of Pretreatment Effects of $\mathrm{FeCl}_{2}$ and Distilled Water}

Biomass is subjected to autohydrolysis at certain temperature conditions, such as $150-240{ }^{\circ} \mathrm{C}$ [46]. Therefore, the catalytic action of an ultra-low concentration of $\mathrm{FeCl}_{2}$ on pretreatment was evaluated by comparing with distilled water under the same pretreatment conditions. The pretreatment influences of $\mathrm{FeCl}_{2}$ and distilled water on the yields of glucose, xylose, and arabinose in the reaction solution are shown in Figure 3.

Figure 3a shows the effects of both an ultra-low concentration of $\mathrm{FeCl}_{2}$ and distilled water on the yield of glucose under different pretreatment conditions, including temperature and concentration. It can be seen that the yield of glucose resulted from various $\mathrm{FeCl}_{2}$ solutions are higher than that caused by distilled water at the same temperature. This indicated that an ultra-low concentration of $\mathrm{FeCl}_{2}$ can strengthen the destruction of the cellulose structure and produce more glucose. However, the yield of glucose declined with increasing temperature, this implied that the glucose degraded partly at high temperature.

In Figure $3 \mathrm{~b}$, the yield of xylose with $\mathrm{FeCl}_{2}$ pretreatment was also notably higher than that of distilled water, and more xylose was obtained than glucose in a short time. It indicated that $\mathrm{FeCl}_{2}$ exhibited high catalytic activity for hemicellulose degradation and xylose release. Additionally, Figure $3 b$ showed different variations compared with Figure 3a. As the temperature went up, xylose production increased rapidly and reached the maximum value at $180{ }^{\circ} \mathrm{C}$ with different $\mathrm{FeCl}_{2}$ pretreatments, and there was no obvious change from $180^{\circ} \mathrm{C}$ to $200{ }^{\circ} \mathrm{C}$. Different from $\mathrm{FeCl}_{2}$ pretreatments, xylose yield rapidly decreased at $180-200^{\circ} \mathrm{C}$ by distilled water pretreatment. The results showed that the increase in temperature had a great effect on straw self-hydrolysis. Xylose produced by an ultra-low concentration of $\mathrm{FeCl}_{2}$ at $220{ }^{\circ} \mathrm{C}$ was not much different from that produced by distilled water, because hemicellulose had already been mostly degraded, and xylose had undergone secondary degradation the same as glucose. It can be seen that $\mathrm{FeCl}_{2}$ played its catalytic role better at a temperature below $220^{\circ} \mathrm{C}$.

In Figure $3 \mathrm{c}, \mathrm{FeCl}_{2}$ had a significant catalytic effect on arabinose production, which was the same as that of glucose and xylose. Although the curve in Figure $3 \mathrm{c}$ had a similar downward trend as in Figure $3 a$, the slope of Figure $3 c$ was larger, which indicated that the output of arabinose decreases faster with increasing temperature. When the temperature went up above $200^{\circ} \mathrm{C}$, the yield of arabinose dropped to below $1 \mathrm{~g}$ and changed little. It indicated that most of the arabinose in the solution was degraded. 

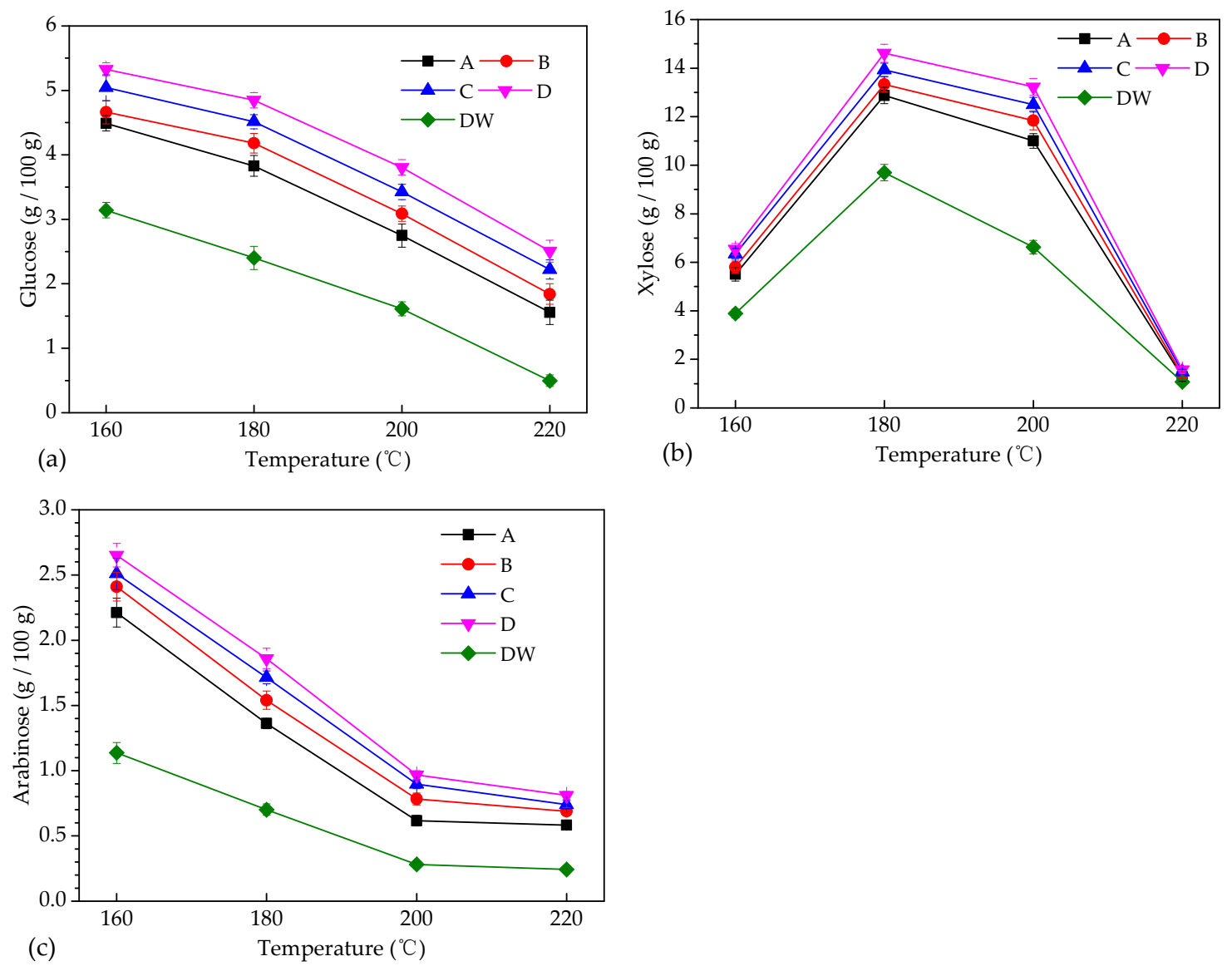

Figure 3. Comparison of pretreatment effects of an ultra-low concentration of $\mathrm{FeCl}_{2}$ and distilled water on corn straw with the reaction temperature of $160{ }^{\circ} \mathrm{C}, 180{ }^{\circ} \mathrm{C}, 200{ }^{\circ} \mathrm{C}, 220^{\circ} \mathrm{C}$, and the time of $20 \mathrm{~min}$. The amount of sugar produced in the reaction solution are as follows: (a) glucose; (b) xylose; (c) arabinose; Legend. $\mathrm{DW}(\bullet), \mathrm{A}(\boldsymbol{\bullet}), \mathrm{B}(\bullet), \mathrm{C}(\boldsymbol{\Delta})$ and $\mathrm{D}(\boldsymbol{\nabla})$ represent distilled water, $1 \times 10^{-5} \mathrm{~mol} / \mathrm{L}$, $5 \times 10^{-5} \mathrm{~mol} / \mathrm{L}, 1 \times 10^{-4} \mathrm{~mol} / \mathrm{L}$, and $5 \times 10^{-4} \mathrm{~mol} / \mathrm{L}$, respectively.

As can be seen from Figure $3 \mathrm{a}-\mathrm{c}, \mathrm{FeCl}_{2}$ compared with distilled water played a more positive role to promote straw degradation because more monosaccharides were produced. This indicated that $\mathrm{FeCl}_{2}$ had an excellent catalytic performance. In view of the optimization of the whole process from pretreatment to fermentation, the minimum amount of $\mathrm{FeCl}_{2}$ should be considered for the optimal performance of the anaerobic system. As $1 \times 10^{-5} \mathrm{~mol} / \mathrm{L} \mathrm{FeCl}_{2}$ can give promising degradation results and has an economical advantage due to its low concentration, the minimum amount would be further studied to evaluate the effect of an ultra-low concentration of $\mathrm{FeCl}_{2}$ on straw hydrolysis as well as fermentation.

\subsubsection{Microstructure Comparison by the Pretreatment of $\mathrm{FeCl}_{2}$ and Distilled Water}

Figure 4 shows the microscopic morphology of straw in different pretreatment conditions. It can be seen that untreated corn straw was broken in a small part due to mechanical action during sample preparation in Figure 4a. Most of its surface was smooth, and the long chain of cellulose is clearly visible. However, there are different damage degrees for the straw surface after the pretreatment of distilled water and $\mathrm{FeCl}_{2}$ in Figure $4 \mathrm{~b}$,c. In Figure $4 \mathrm{~b}$, the straw only had a little damage on the surface. Some of the fibers were detached and the fiber long chain can be recognized after the hydrolysis of distilled water. In Figure 4c, the straw was damaged seriously after the hydrolysis of $\mathrm{FeCl}_{2}$. The cellulose long chain was obviously broken. The dense structure was widely opened and the surface was stratified and no longer smooth. The roughness of the straw surface increased greatly [47], 
indicating a major degradation of hemicellulose [48]. It was quite clear that $\mathrm{FeCl}_{2}$ showed a stronger influence on straw hydrolysis than distilled water from the damage degree of straw. It indicated an ultra-low concentration of $\mathrm{FeCl}_{2}$ had an excellent catalytic performance to degrade straw. This was in agreement with the results shown in Figure 3.

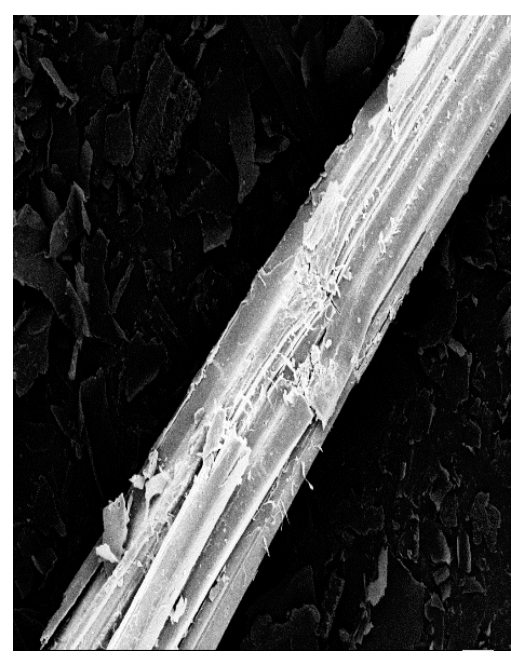

(a)

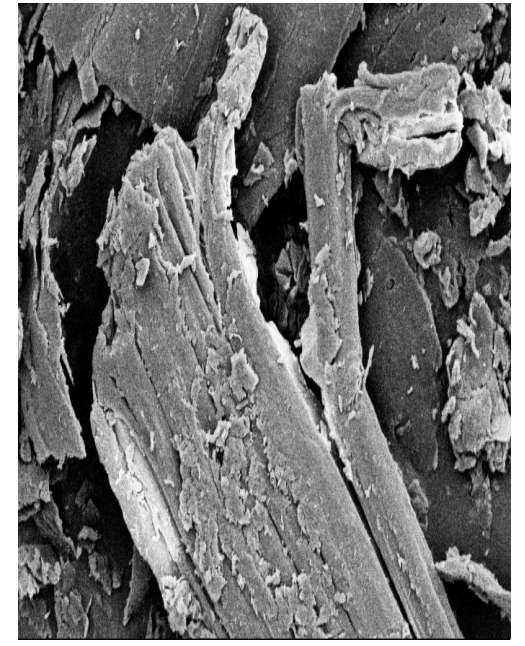

(b)

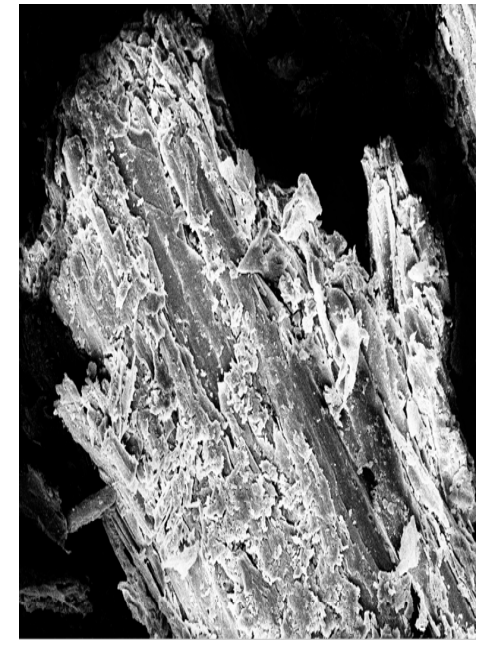

(c)

Figure 4. SEM images (at a 500 magnification) of untreated straw and the pretreatment samples by distilled water and $\mathrm{FeCl}_{2}$ at $180{ }^{\circ} \mathrm{C}$ and $10 \mathrm{~min}$. (a) untreated corn straw; (b) pretreated with distilled water; (c) pretreated with $1 \times 10^{-5} \mathrm{~mol} / \mathrm{L} \mathrm{FeCl}_{2}$.

\subsection{Effect of an Ultra-Low Concentration of $\mathrm{FeCl}_{2}$ on Cellulose Hydrolysis}

Figure 5 exhibits the effect of $1 \times 10^{-5} \mathrm{~mol} / \mathrm{L} \mathrm{FeCl}_{2}$ pretreatment on cellulose degradation with four products, including glucose, 5-HMF, levulinic acid, and formic acid [49]. As seen in Figure 5, when $C S$ was low between -3.08 and -2.14 , more glucose was obtained and the content of glucose reached the maximum value of $5.7 \mathrm{~g}$ at $180{ }^{\circ} \mathrm{C}$ and $10 \mathrm{~min}$. Meanwhile, cellulose degradation also reached the highest value of $36.06 \%$. By comparison, the degradation of cellulose was not more than $25 \%$ when corn stalk was pretreated with $0.1 \mathrm{~mol} / \mathrm{L} \mathrm{FeSO}_{4}$ at $140-200{ }^{\circ} \mathrm{C}$ [4]. With the increase of CS, the glucose yield in the solution fluctuated up and down and overall, showed a decreasing trend. Unlike glucose, 5-HMF increased with temperature and time. It indicated that glucose is easier to be further decomposed to 5 -HMF above $220^{\circ} \mathrm{C}$. In other words, the high temperature would promote glucose degradation and produce more 5-HMF.

5-HMF is thought to inhibit the fermentation process and thus affect methane production [50]. Under different pretreatment conditions, the yields of 5-HMF were very low, in the range of 0.09-1.9 $\mathrm{g} / 100 \mathrm{~g}$. Additionally, the high temperature may inhibit levulinic acid production. Because levulinic acid is a hydrolysate of 5-HMF [51], its amount reflects the hydrolysis degree of 5-HMF. It could be seen that the content of levulinic acid increased with increasing $C S$ below $220^{\circ} \mathrm{C}$. When $C S$ reached -1.56 , that is, the reaction condition was $200^{\circ} \mathrm{C}$ and $20 \mathrm{~min}$, the yield of levulinic acid reached its peak at $4.09 \mathrm{~g}$ and then decreased continuously between $200^{\circ} \mathrm{C}$ and $220^{\circ} \mathrm{C}$. It dropped to a minimum of 0.66 $\mathrm{g}$ at $240^{\circ} \mathrm{C}$ although there was a small rebound. Obviously, the amounts of formic acid and levulinic acid were higher than 5-HMF below $220^{\circ} \mathrm{C}$. It indicated that 5-HMF was degraded in a large amount.

Combined with cellulose degradation, it can be concluded that the pretreatment conditions with medium or low CS can not only improve the degradation of cellulose but also provide more available substrates for subsequent fermentation. More importantly, the yields of 5-HMF were extremely low with $1 \times 10^{-5} \mathrm{~mol} / \mathrm{L} \mathrm{FeCl} 2$ pretreatments, so that it would not have a significant inhibitory effect on subsequent anaerobic fermentation. 


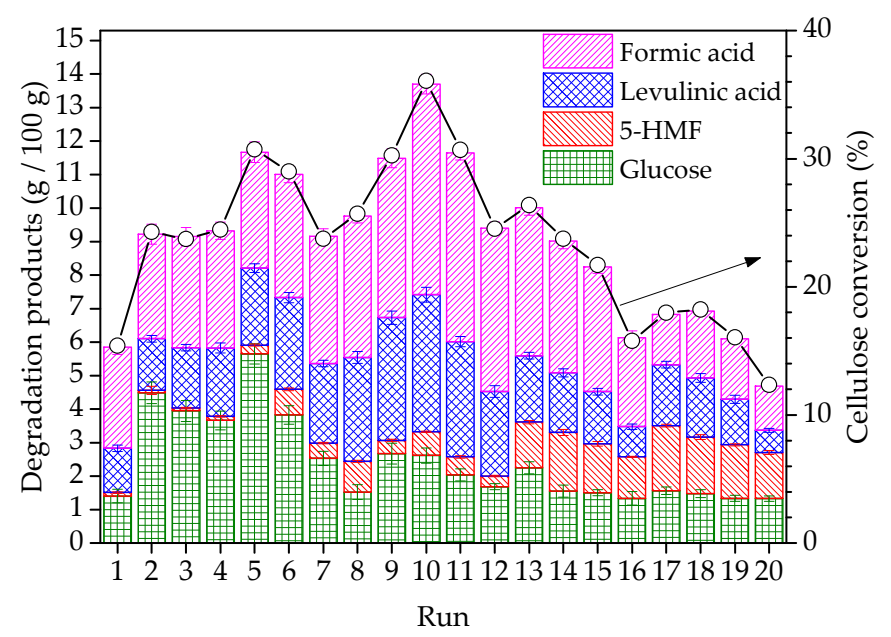

Figure 5. Effect of $1 \times 10^{-5} \mathrm{~mol} / \mathrm{L} \mathrm{FeCl}_{2}$ pretreatment on cellulose degradation.

\subsection{Effect of an Ultra-Low Concentration of $\mathrm{FeCl}_{2}$ on Hemicellulose Hydrolysis}

Figure 6 shows the influence of different conditions on hemicellulose and its main products including xylose, arabinose, and furfural. It is shown that the yield of xylose fluctuated as CS increased. At $180^{\circ} \mathrm{C}$ and $10 \mathrm{~min}$, it reached a maximum of $16.3 \mathrm{~g}$. Additionally, the arabinose yield and hemicellulose degradation all reach the maximum at the same condition, where the maximum glucose yield was also obtained. It indicated that this reaction condition was more favorable for monosaccharide production. When $C S$ was higher than $-1.83\left(200^{\circ} \mathrm{C}, 10 \mathrm{~min}\right)$, xylose yield decreased significantly. Nevertheless, furfural yield increased continuously and reached a maximum value of $5.9 \mathrm{~g}$ at $220^{\circ} \mathrm{C}$ and $10 \mathrm{~min}$. It showed that more xylose was degraded to furfural and other by-products at the harsher pretreatment condition. It is noted that furfural, like 5-HMF, is considered as an inhibitor of fermentation [51]. So, rather more xylose and arabinose than furfural are needed. It can be seen that the change trends of cellulose and hemicellulose were similar, which was consistent with the reported results [22]. The degradation of hemicellulose of $97.6 \%$ was achieved at $180{ }^{\circ} \mathrm{C}$ and $10 \mathrm{~min}$. It was far higher than that of cellulose compared with Figure 5. This is related to the amorphous structure of hemicellulose.

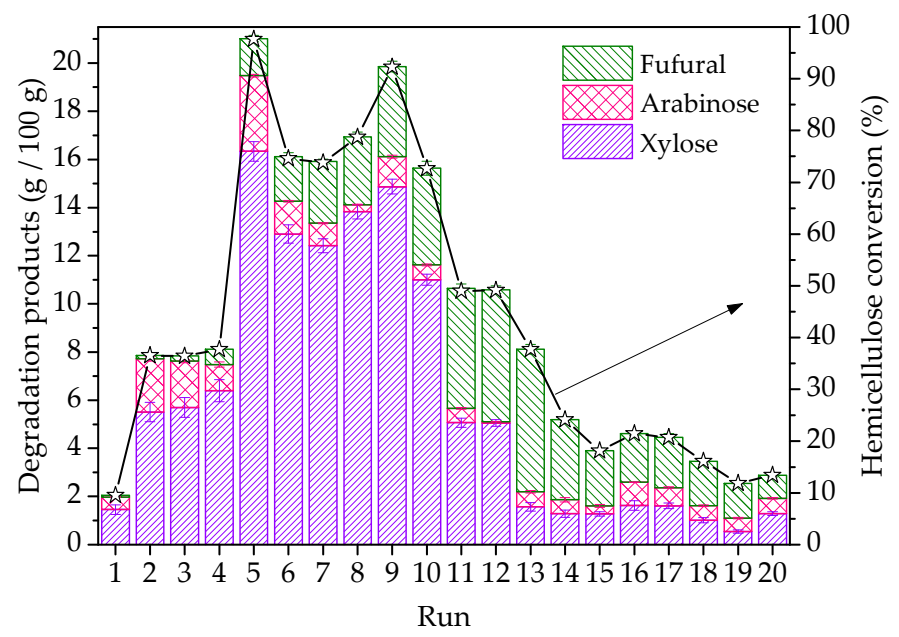

Figure 6. Effect of $1 \times 10^{-5} \mathrm{~mol} / \mathrm{L} \mathrm{FeCl}_{2}$ pretreatment on hemicellulose degradation.

\subsection{Effect of Ultra-Low Concentration of $\mathrm{FeCl}_{2}$ on the $\mathrm{pH}$ Value}

Figure 7 shows the relations between the $\mathrm{pH}$ after reaction and two main acid products, including formic acid and acetic acid, in the hydrolysate. Formic acid and acetic acid are two important organic 
acids produced in the hydrolysates. As can be seen, the content of formic acid was always higher than that of acetic acid in the temperature range of $160-200{ }^{\circ} \mathrm{C}$. It is a fact that formic acid mainly comes from the degradation of 5-HMF and acetic acid is from the acetyl in the lignocellulose [2,51]. This indicated that 5-HMF degrades faster than the acetyl group within this range. Formic acid can be conversed to biogas directly in the anaerobic digestion [2], while acetic acid is considered as an inhibitor of fermentation activity [52]. When the temperature rose to $220{ }^{\circ} \mathrm{C}$, the concentration of acetic acid increased rapidly, while formic acid drops sharply. Combined with Figures 5 and 7, it indicated that inhibitors such as acetic acid, furfural, and 5-HMF, were more likely to be produced at high temperatures above $220^{\circ} \mathrm{C}$. As a result, the reaction temperature should be controlled below $220^{\circ} \mathrm{C}$ to limit the generation of inhibitors.

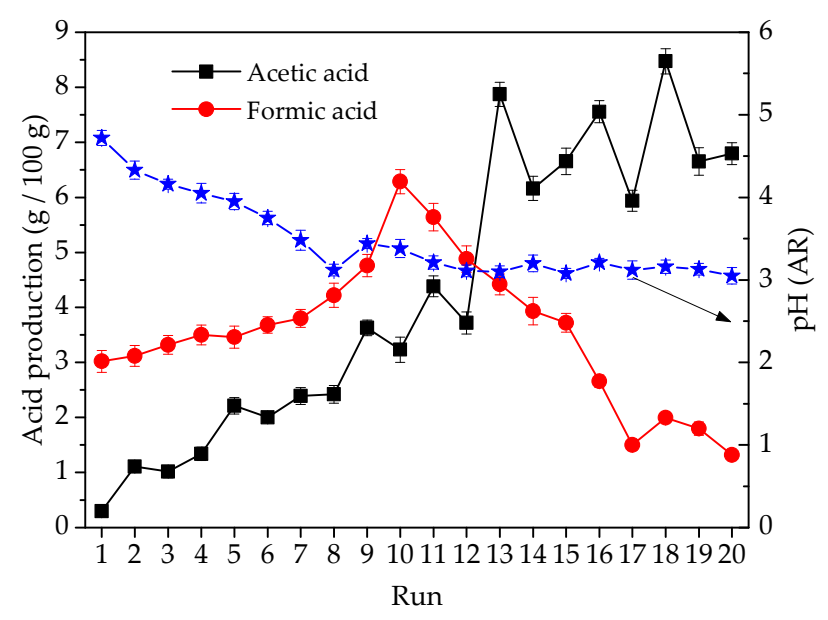

Figure 7. Effect of $1 \times 10^{-5} \mathrm{~mol} / \mathrm{L} \mathrm{FeCl}_{2}$ pretreatment on acid production.

Because of the higher yields of formic acid and acetic acid, they significantly affected the $\mathrm{pH}$ value of the solution after the reaction. It can be seen from Table 1 that the $\mathrm{pH}$ of the solution before the reaction was in the range of 5.75-5.9. It gradually decreased from 4.72 to 3.05 as $C S$ rose. The $\mathrm{pH}$ is an important factor during biomass conversion, the change of that reflected the amount of acid produced after the pretreatment.

\subsection{Effect of an Ultra-Low Concentration of $\mathrm{FeCl}_{2}$ on Total Hydrolysates}

Furfural and 5-HMF have been considered inhibitors to hinder anaerobic fermentation. However, recent research [53] found that pretreatment helps to dissolve or alter lignin structure and enlarge methane yield. Furthermore, furfural and 5-HMF as pretreatment by-products did not inhibit anaerobic digestion at a certain concentration and could be used as a carbon source to lead to biogas production. Furfural and 5-HMF can be converted into methane by methanogenic microorganisms at a concentration of $1 \mathrm{~g} / \mathrm{L}$ and in the presence of xylose at $1 \mathrm{~g} / \mathrm{L}$. Some researchers have found that furfural and HMF will inhibit the anaerobic microbial growth or metabolic processes when their concentration is higher than $1.9 \mathrm{~g} / \mathrm{L}$ and $2.5 \mathrm{~g} / \mathrm{L}$, respectively [2]. Additionally, it has been proved that the microbial community had a good ability to adapt the inhibitors, such as furfural, HMF, and phenol compounds, after 57 days of biogas production [54]. Therefore, according to these studies, pretreatment conditions including temperature, catalyst concentration, and reaction time, need to be investigated more comprehensively. Not only sugar yield and the inhibition of by-products but also the possible positive effects of by-products on fermentation should be considered.

As can be seen from Figure 8a, total sugar production increased sharply with low CS. When CS exceeded $-2.4\left(180^{\circ} \mathrm{C}, 10 \mathrm{~min}\right)$, the yields of total sugar began to decline rapidly until it remained at a low level. The change in the trend of the total by-product was relatively gentle compared with total sugar. It illustrated that the effect of CS on total sugar yield was higher than that of the by-product. 
The variation trend of total sugar and the total by-product was consistent with the theoretical correlation between the combined severity factor and the reaction degree [39].
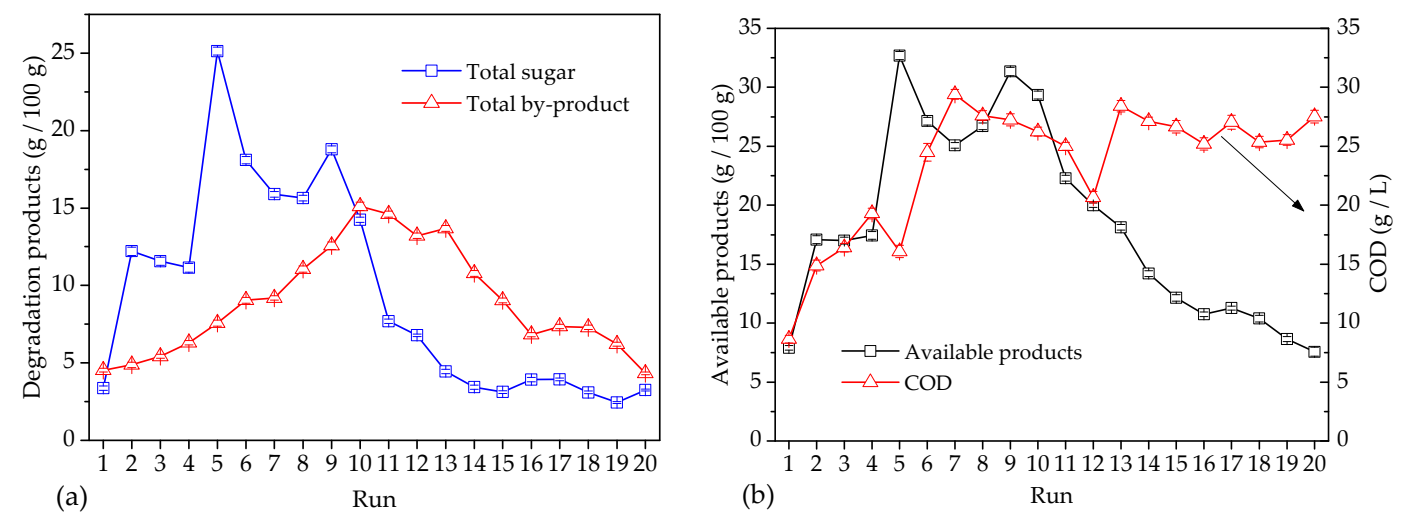

Figure 8. Effect of $1 \times 10^{-5} \mathrm{~mol} / \mathrm{L} \mathrm{FeCl}_{2}$ pretreatment on total products and COD. (a) Total sugar and total by-product, (b) Available products and COD.

In order to increase biogas production from biomass, available products containing total sugar and total by-products should be as much as possible. In Figure $8 \mathrm{~b}$, available products reached a peak of $32.7 \mathrm{~g}$ at $180^{\circ} \mathrm{C}$ and $10 \mathrm{~min}$. However, to find out the optimum condition of $\mathrm{FeCl}_{2}$ pretreatment, the favorable concentration of furfural and 5-HMF should be considered. According to the previous literature, the concentration of furfural and HMF is suggested to be lower than 15-20 mm which is no inhibition for the anaerobic fermentation. Therefore, combined with the yield of furfural and 5-HMF in Figures 5 and 6, a conclusion can be reached that the optimum condition of $1 \times 10^{-5} \mathrm{~mol} / \mathrm{L} \mathrm{FeCl}_{2}$ pretreatment was a reaction temperature of $180^{\circ} \mathrm{C}$ and holding time of $10 \mathrm{~min}$. Additionally, the value of COD in the solution did not fluctuate greatly above $200^{\circ} \mathrm{C}$, while the available products dropped sharply. It was speculated that many other small organic molecules were also formed at such high reaction intensity.

\subsection{Mass Balance during Ultra-Low Concentration of $\mathrm{FeCl}_{2}$ Pretreatment}

In Figure 9, the organic products as important carbon sources for subsequent fermentation were not less than $77.5 \%$ of COD in the liquid fraction under the optimal condition. The content of the main by-products only accounted for $18 \%$ of all organic products. Among all the by-products, the production of 5-HMF, furfural, and acetic acid are low, $0.3 \mathrm{~g}, 1.5 \mathrm{~g}$, and $2.2 \mathrm{~g}$, respectively. Moreover, $30.7 \%$ of cellulose conversed, and $69.6 \%$ of lignin was degraded. In particular, the release of xylose was as high as $95 \%$ and the conversion of hemicellulose reached $97.6 \%$. It indicated that the ultra-low concentration of $\mathrm{FeCl}_{2}$ had a significantly positive impact on hemicellulose removal and xylose release.

\subsection{Effect of Pretreatment on Acid Fermentation}

The effect of pretreatment on acid fermentation was evaluated with the hydrolyzate of the optimum pretreatment. The concentration of main volatile fatty acids (VFAs) and the variation of the $\mathrm{pH}$ during acidogenic fermentation were shown in Figure 10. 


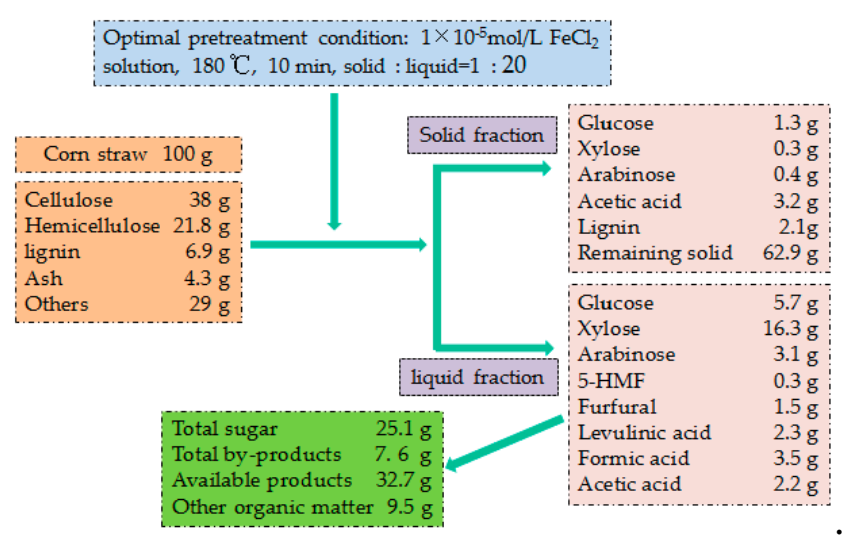

Figure 9. Mass balance of treated corn straw under the optimal condition of $1 \times 10^{-5} \mathrm{~mol} / \mathrm{L}$ $\mathrm{FeCl}_{2}$ pretreatment.
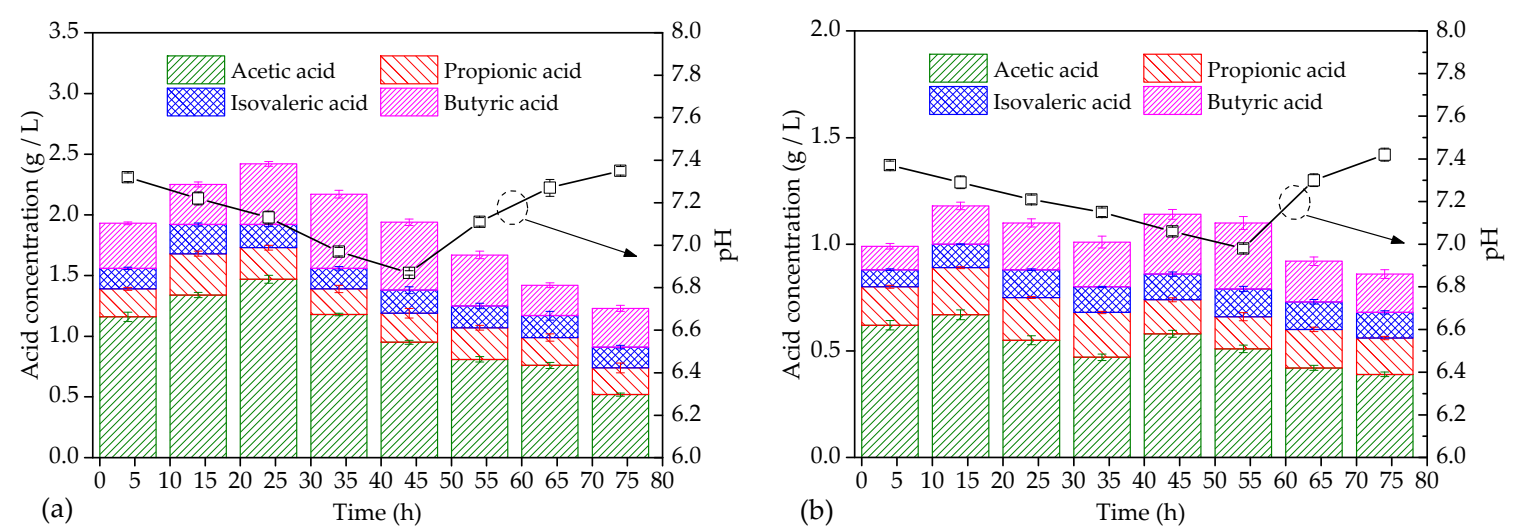

Figure 10. VFAs distribution and the $\mathrm{pH}$ during acidogenic fermentation with the hydrolyzate. (a) $1 \times 10^{-5} \mathrm{~mol} / \mathrm{L} \mathrm{FeCl}_{2}$ (bottle $1^{\#}$ ); (b) distilled water (bottle $2^{\#}$ ).

The production of acetic acid was the most in all products, which was the important organic compound to be utilized during the anaerobic fermentation process [34]. The sum of acetic acid and butyric acid accounts for more than $70 \%$ during $26 \mathrm{~h}$ to $54 \mathrm{~h}$ in bottle $1^{\#}$, exhibiting the feature of butyric acid fermentation type $[55,56]$. The $\mathrm{pH}$ of bottle $1^{\#}$ dropped quickly between 0 and $44 \mathrm{~h}$ and reached its lowest point at $44 \mathrm{~h}$ in Figure 10a. Compared with that in bottle $1^{\#}$, butyric acid-type fermentation took place between $44 \mathrm{~h}$ and $54 \mathrm{~h}$ in bottle $2^{\#}$, and the lowest $\mathrm{pH}$ appeared relatively late at $54 \mathrm{~h}$ in Figure 10b. It was obvious that the acidification process proceeded faster, and more VFAs were produced in bottle $1^{\#}$ than those in bottle $2^{\#}$. It indicated that the $\mathrm{FeCl}_{2}$ pretreatment accelerated the acidogenic fermentation process and promoted the production of organic acids.

In summary, the ultra-low concentration of $\mathrm{FeCl}_{2}$ not only improved the effect of straw degradation as the pretreatment catalyst but also directly served as the nutritional supplement for subsequent fermentation, which avoided repeated addition of nutrients and greatly reduced the cost of raw material and labor. Low requirements for equipment saved the cost of the device due to slight corrosion by the ultra-low concentration of $\mathrm{FeCl}_{2}$. Moreover. the hydrolysate after $\mathrm{FeCl}_{2}$ pretreatment can effectively improve the potential of straw to biogas.

\section{Conclusions}

This work proposed an economical and efficient method for the conversion of biomass to biogas. Based on the whole process optimization of biomass conversion, combined with the recommended minimum amount of $\mathrm{FeCl}_{2}$ as a nutritional composition in the anaerobic system, the pretreatment effects of an ultra-low concentration of $\mathrm{FeCl}_{2}$ on corn straw were investigated. The remarkable catalytic role 
of $\mathrm{FeCl}_{2}$ was confirmed by comparison with distilled water pretreatment. An ultra-low concentration of $\mathrm{FeCl}_{2}$ as the catalyst showed significant effects on hemicellulose hydrolysis and xylose release in the pretreatment. The optimized condition of $1 \times 10^{-5} \mathrm{~mol} / \mathrm{L} \mathrm{FeCl}_{2}$ pretreatment that combined the influence of total sugars and total by-products on fermentation, was found to be the temperature of $180^{\circ} \mathrm{C}$ and the holding time of $10 \mathrm{~min}$. At this condition, $\mathrm{FeCl}_{2}$ pretreatment accelerated the acidogenic fermentation process and increased organic acid yields. These results will help to enhance the potential of straw to biogas.

Author Contributions: Y.Q. performed pretreatment experiments, data analysis and paper writing; X.L. provided financial support and determination of experimental scheme; Z.Z. helped to collect the raw material and set up experimental equipment; S.Z. provided writing guidance and language modification of the full paper. All authors contributed to the editing and reviewing of the document. All authors have read and agreed to the published version of the manuscript.

Funding: This research was funded by National Natural Science Foundation Project, China, 51876180.

Conflicts of Interest: The authors declare no conflict of interest.

\section{References}

1. Dai, B.; Guo, X.; Yuan, D.; Xu, J. Comparison of Different Pretreatments of Rice Straw Substrate to Improve Biogas Production. Waste Biomass Valorization 2018, 9, 1503-1512. [CrossRef]

2. Zheng, Y.; Zhao, J.; Xu, F.; Li, Y. Pretreatment of lignocellulosic biomass for enhanced biogas production. Prog. Energy Combust. Sci. 2014, 42, 35-53. [CrossRef]

3. Wang, P.; Howard, B.H. Impact of Thermal Pretreatment Temperatures on Woody Biomass Chemical Composition, Physical Properties and Microstructure. Energies 2018, 11, 25. [CrossRef]

4. Zhao, J.; Zhang, H.; Zheng, R.; Lin, Z.; Huang, H. The enhancement of pretreatment and enzymatic hydrolysis of corn stover by $\mathrm{FeSO}_{4}$ pretreatment. Biochem. Eng. J. 2011, 56, 158-164. [CrossRef]

5. Mosier, N. Features of promising technologies for pretreatment of lignocellulosic biomass. Bioresour. Technol. 2005, 96, 673-686. [CrossRef]

6. Galbe, M.; Zacchi, G. Pretreatment of Lignocellulosic Materials for Efficient Bioethanol Production; Springer: Berlin/Heidelberg, Germany, 2007; Volume 108, pp. 41-65.

7. Fernandes, M.C.; Ferro, M.D.; Paulino, A.F.C.; Chaves, H.T.; Evtuguin, D.V.; Xavier, A.M.R.B. Comparative study on hydrolysis and bioethanol production from cardoon and rockrose pretreated by dilute acid hydrolysis. Ind. Crop. Prod. 2018, 111, 633-641. [CrossRef]

8. Zhang, B.; Wang, L.; Shahbazi, A.; Diallo, O.; Whitmore, A. Dilute-sulfuric acid pretreatment of cattails for cellulose conversion. Bioresour. Technol. 2011, 102, 9308-9312. [CrossRef]

9. Salehian, P.; Karimi, K.; Zilouei, H.; Jeihanipour, A. Improvement of biogas production from pine wood by alkali pretreatment. Fuel 2013, 106, 484-489. [CrossRef]

10. Ghasemian, M.; Zilouei, H.; Asadinezhad, A. Enhanced Biogas and Biohydrogen Production from Cotton Plant Wastes Using Alkaline Pretreatment. Energy Fuels 2016, 30, 10484-10493. [CrossRef]

11. Mosier, N.; Hendrickson, R.; Ho, N.; Sedlak, M.; Ladisch, M.R. Optimization of pH controlled liquid hot water pretreatment of corn stover. Bioresour. Technol. 2005, 96, 1986-1993. [CrossRef]

12. Kim, Y.; Kreke, T.; Mosier, N.S.; Ladisch, M.R. Severity factor coefficients for subcritical liquid hot water pretreatment of hardwood chips. Biotechnol. Bioeng. 2014, 111, 254-263. [CrossRef] [PubMed]

13. Lizasoain, J.; Trulea, A.; Gittinger, J.; Kral, I.; Piringer, G.; Schedl, A.; Nilsen, P.J.; Potthast, A.; Gronauer, A.; Bauer, A. Corn stover for biogas production: Effect of steam explosion pretreatment on the gas yields and on the biodegradation kinetics of the primary structural compounds. Bioresour. Technol. 2017, 244, 949-956. [CrossRef] [PubMed]

14. Bauer, A.; Lizasoain, J.; Theuretzbacher, F.; Agger, J.W.; Rincón, M.; Menardo, S.; Saylor, M.K.; Enguídanos, R.; Nielsen, P.J.; Potthast, A.; et al. Steam explosion pretreatment for enhancing biogas production of late harvested hay. Bioresour. Technol. 2014, 166, 403-410. [CrossRef] [PubMed]

15. Allison, B.J.; Cádiz, J.C.; Karuna, N.; Jeoh, T.; Simmons, C.W. The Effect of Ionic Liquid Pretreatment on the Bioconversion of Tomato Processing Waste to Fermentable Sugars and Biogas. Appl. Biochem. Biotechnol. 2016, 179, 1227-1247. [CrossRef] [PubMed] 
16. Gao, J.; Chen, L.; Yan, Z.; Wang, L. Effect of ionic liquid pretreatment on the composition, structure and biogas production of water hyacinth (Eichhornia crassipes). Bioresour. Technol. 2013, 132, 361-364. [CrossRef]

17. Cao, L.; Chen, H.; Tsang, D.C.W.; Luo, G.; Hao, S.; Zhang, S.; Chen, J. Optimizing xylose production from pinewood sawdust through dilute-phosphoric-acid hydrolysis by response surface methodology. J. Clean. Prod. 2018, 178, 572-579. [CrossRef]

18. Bhandari, N.; Macdonald, D.G.; Bakhshi, N.N. Kinetic studies of corn stover saccharification using sulphuric acid. Biotechnol. Bioeng. 1984, 26, 320-327. [CrossRef]

19. Wyman, C.E.; Dale, B.E.; Elander, R.T.; Holtzapple, M.; Ladisch, M.R.; Lee, Y.Y. Coordinated development of leading biomass pretreatment technologies. Bioresour. Technol. 2005, 96, 1959-1966. [CrossRef]

20. Wyman, C.E.; Dale, B.E.; Elander, R.T.; Holtzapple, M.; Ladisch, M.R.; Lee, Y.Y.; Mitchinson, C.; Saddler, J.N. Comparative sugar recovery and fermentation data following pretreatment of poplar wood by leading technologies. Biotechnol. Prog. 2009, 25, 333-339. [CrossRef]

21. Yan, Y.; Li, T.; Ren, Z.; Li, G. A study on catalytic hydrolysis of peat. Bioresour. Technol. 1996, 57, $269-273$. [CrossRef]

22. Liu, L.; Sun, J.; Cai, C.; Wang, S.; Pei, H.; Zhang, J. Corn stover pretreatment by inorganic salts and its effects on hemicellulose and cellulose degradation. Bioresour. Technol. 2009, 100, 5865-5871. [CrossRef] [PubMed]

23. Sun, Y.; Lu, X.; Zhang, S.; Zhang, R.; Wang, X. Kinetic study for Fe $\left(\mathrm{NO}_{3}\right)_{3}$ catalyzed hemicellulose hydrolysis of different corn stover silages. Bioresour. Technol. 2011, 102, 2936-2942. [CrossRef] [PubMed]

24. Yu, Q.; Zhuang, X.; Yuan, Z.; Qi, W.; Wang, Q.; Tan, X. The effect of metal salts on the decomposition of sweet sorghum bagasse in flow-through liquid hot water. Bioresour. Technol. 2011, 102, 3445-3450. [CrossRef] [PubMed]

25. Demirel, B.; Scherer, P. Trace element requirements of agricultural biogas digesters during biological conversion of renewable biomass to methane. Biomass Bioenergy 2011, 35, 992-998. [CrossRef]

26. Qiang, H.; Lang, D.; Li, Y. High-solid mesophilic methane fermentation of food waste with an emphasis on Iron, Cobalt, and Nickel requirements. Bioresour. Technol. 2012, 103, 21-27. [CrossRef]

27. Zandvoort, M.H.; van Hullebusch, E.D.; Fermoso, F.G.; Lens, P.N.L. Trace Metals in Anaerobic Granular Sludge Reactors: Bioavailability and Dosing Strategies. Eng. Life Sci. 2006, 6, 293-301. [CrossRef]

28. Takashima, M.; Shimada, K.; Speece, R.E. Minimum requirements for trace metals (iron, nickel, cobalt, and zinc) in thermophilic and mesophilic methane fermentation from glucose. Water Environ. Res. 2011, 83, 339-346. [CrossRef]

29. Zaleckas, E.; Sendžikienè, E.; Čiutelytė, R. Evaluation of Heavy Metals Influence on Biogas Production. Environ. Res. Eng. Manag. 2012, 62, 14-20. [CrossRef]

30. Bryant, M.P. Microbial methane production-theoretical aspects. J. Anim. Sci. 1979, 1, 193-201. [CrossRef]

31. Qiang, H.; Niu, Q.; Chi, Y.; Li, Y. Trace metals requirements for continuous thermophilic methane fermentation of high-solid food waste. Chem. Eng. J. 2013, 222, 330-336. [CrossRef]

32. Preeti Rao, P.; Seenayya, G. Improvement of methanogenesis from cow dung and poultry litter waste digesters by addition of iron. World J. Microbiol. Biotechnol. 1994, 10, 211-214. [CrossRef] [PubMed]

33. Osuna, M.B.; Zandvoort, M.H.; Iza, J.M.; Lettinga, G.; Lens, P.N.L. Effects of trace element addition on volatile fatty acid conversions in anaerobic granular sludge reactors. Environ. Technol. 2003, 5, 573-587. [CrossRef] [PubMed]

34. Qiao, Y.; Lu, X.; Zhang, S. Simultaneously improving pretreatment and anaerobic acidification effects on corn stalk by low concentration of $\mathrm{FeCl}_{2}$ solution. Energy Sources Part A Recovery Util. Environ. Eff. 2018, 40, 759-764. [CrossRef]

35. Takashima, M.; Speece, R.E. Mineral nutrient requirements for high-rate methane fermentation of acetate at low SRT. Res. J. Water Pollut. Control Fed. 1989, 61, 1645-1650.

36. Hoban, D.J.; Berg, L. Effect of Iron on Conversion of Acetic Acid to Methane During Methanogenic Fermentations. J. Appl. Bacteriol. 1979, 47, 153-159. [CrossRef]

37. Chakraborty, N.; Chatterjee, M.; Sarkar, G.M.; Lahiri, S.C. Inhibitory Effects of the Divalent Metal Ions on Biomethanation by Isolated Mesophilic Methanogen in AC21 Medium in Presence or Absence of Juices from Water Hyacinth. BioEnergy Res. 2010, 3, 314-320. [CrossRef]

38. Sluiter, A.; Ruiz, B.H.R.; Sluiter, J.; Templeton, D. Biomass Analysis Technology Team Laboratory Analytical Procedures: Determination of Structural Carbohydrates and Lignin in Biomass, NREL Laboratory Analytical Procedures for Standard Biomass Analysis; NREL: Golden, CO, USA, 2006. 
39. De Farias Silva, C.E.; Bertucco, A. Severity Factor as an Efficient Control Parameter to Predict Biomass Solubilization and Saccharification During Acidic Hydrolysis of Microalgal Biomass. BioEnergy Res. 2018, 11, 491-504. [CrossRef]

40. Overend, R.P.; Chornet, E. Fractionation of lignocellulosics by steam-aqueous pretreatments. Philos. Trans. R. Soc. London. Ser. A, Math. Phys. Sci. 1987, 321, 523-536.

41. Chum, H.L.; Johnson, D.K.; Black, S.K.; Overend, R.P. Pretreatment-Catalyst effects and the combined severity parameter. Appl. Biochem. Biotechnol. 1990, 24-25, 1-14. [CrossRef]

42. Lloyd, T.A.; Wyman, C.E. Combined sugar yields for dilute sulfuric acid pretreatment of corn stover followed by enzymatic hydrolysis of the remaining solids. Bioresour. Technol. 2005, 96, 1967-1977. [CrossRef]

43. China, E. Standard Methods for the Examination of Water and Wastewater, 4th ed.; National Environment Protection Agency: Beijing, China, 2002; p. 4.

44. Lin, C.; Cheng, C. Fermentative hydrogen production from xylose using anaerobic mixed microflora. Int. J. Hydrogen Energy 2006, 31, 832-840. [CrossRef]

45. Lin, C.; Wu, C.; Wu, J.; Chang, F. Effect of cultivation temperature on fermentative hydrogen production from xylose by a mixed culture. Biomass Bioenergy 2008, 32, 1109-1115. [CrossRef]

46. Carvalheiro, F.; Silva-Fernandes, T.; Duarte, L.C.; Gírio, F.M. Wheat Straw Autohydrolysis: Process Optimization and Products Characterization. Appl. Biochem. Biotechnol. 2009, 153, 84-93. [CrossRef] [PubMed]

47. Abraham, R.E.; Barrow, C.J.; Puri, M. Relationship to reducing sugar production and scanning electron microscope structure to pretreated hemp hurd biomass (Cannabis sativa). Biomass Bioenergy 2013, 58, $180-187$. [CrossRef]

48. Kumar, R.; Mago, G.; Balan, V.; Wyman, C.E. Physical and chemical characterizations of corn stover and poplar solids resulting from leading pretreatment technologies. Bioresour. Technol. 2009, 100, 3948-3962. [CrossRef]

49. Kumar, G.; Cheon, H.; Kim, S. Effects of 5-hydromethylfurfural, levulinic acid and formic acid, pretreatment byproducts of biomass, on fermentative $\mathrm{H}_{2}$ production from glucose and galactose. Int. J. Hydrogen Energy 2014, 39, 16885-16890. [CrossRef]

50. Cheng, J.; Lin, R.; Song, W.; Xia, A.; Zhou, J.; Cen, K. Enhancement of fermentative hydrogen production from hydrolyzed water hyacinth with activated carbon detoxification and bacteria domestication. Int. J. Hydrogen Energy 2015, 40, 2545-2551. [CrossRef]

51. Zhi, Z.; Li, N.; Qiao, Y.; Zheng, X.; Wang, H.; Lu, X. Kinetic study of levulinic acid production from corn stalk at relatively high temperature using $\mathrm{FeCl}_{3}$ as catalyst: A simplified model evaluated. Ind. Crop. Prod. 2015, 76, 672-680. [CrossRef]

52. Casey, E.; Sedlak, M.; Ho, N.W.; Mosier, N.S. Effect of acetic acid and $\mathrm{pH}$ on the cofermentation of glucose and xylose to ethanol by a genetically engineered strain of Saccharomyces cerevisiae. FEMS Yeast Res. 2010, 10, 385-393. [CrossRef]

53. Barakat, A.; Monlau, F.; Steyer, J.; Carrere, H. Effect of lignin-derived and furan compounds found in lignocellulosic hydrolysates on biomethane production. Bioresour. Technol. 2012, 104, 90-99. [CrossRef]

54. Horn, S.J.; Estevez, M.M.; Nielsen, H.K.; Linjordet, R.; Eijsink, V.G.H. Biogas production and saccharification of Salix pretreated at different steam explosion conditions. Bioresour. Technol. 2011, 102, 7932-7936. [CrossRef] [PubMed]

55. Bhatia, D.; Vieth, W.R.; Venkatasubramaniant, K. Steady-State and Transient Behavior in Microbial Methanification: 1. Experimental Results. Biotechnol. Bioeng. 1985, 27, 1192-1198. [CrossRef] [PubMed]

56. Zhao, X.; Wang, L.; Lu, X.; Zhang, S. Pretreatment of corn stover with diluted acetic acid for enhancement of acidogenic fermentation. Bioresour. Technol. 2014, 158, 12-18. [CrossRef] [PubMed]

(C) 2020 by the authors. Licensee MDPI, Basel, Switzerland. This article is an open access article distributed under the terms and conditions of the Creative Commons Attribution (CC BY) license (http://creativecommons.org/licenses/by/4.0/). 